\title{
Optical Characterization of an Eddy-induced Diatom Bloom West of the Island of Hawaii
}

\author{
F. Nencioli ${ }^{1}$, G. Chang ${ }^{2}$, M. Twardowski ${ }^{3}$, and T. D. Dickey ${ }^{1}$ \\ ${ }^{1}$ Ocean Physics Laboratory, Department of Geography, University of California, Santa Barbara, CA 93106, USA \\ ${ }^{2}$ Sea Engineering Inc., 200 Washington St. Suite 210, Santa Cruz, CA 95060, USA \\ ${ }^{3}$ Dept. of Research, WET Labs Inc., Narragansett, RI, 02882, USA
}

Received: 2 July 2009 - Published in Biogeosciences Discuss.: 7 August 2009

Revised: 16 December 2009 - Accepted: 17 December 2009 - Published: 13 January 2010

\begin{abstract}
Optical properties were collected along a transect across cyclonic eddy Opal in the lee of Hawaii during the E-Flux III field experiment (10-27 March 2005). The eddy was characterized by an intense doming of isopycnal surfaces, and by an enhanced Deep Chlorophyll Maximum Layer (DCML) within its core. The phytoplankton bloom was diatom dominated, evidencing an eddy-induced shift in ecological community. Four distinct regions were identified throughout the water column at Opal's core: a surface mixed layer dominated by small phytoplankton; a layer dominated by "senescent" diatoms between the bottom of the upper mixed layer and the DCML; the DCML; and a deep layer characterized by decreasing phytoplankton activity. We focused on two parameters, the ratio of chlorophyll concentration to particulate beam attenuation coefficient, $[\mathrm{chl}] / c_{\mathrm{p}}$, and the backscattering ratio (the particle backscattering to particle scattering ratio), $\tilde{b}_{\mathrm{bp}}$, and tested their sensitivity to the changes in particle composition observed through the water column at the eddy center. Our results show that $[\mathrm{chl}] / c_{\mathrm{p}}$ is not a good indicator. Despite the shift in ecological community, the ratio remains controlled primarily by the variation in chlorophyll concentration per cell with depth (photoadaptation), so that its values increase throughout the DCML. Steeper increase of $[\mathrm{chl}] / c_{\mathrm{p}}$ below the DCML suggest that remineralization might be another important controlling factor. On the other hand, $\tilde{b}_{\mathrm{bp}}$ clearly indicates a shift from a small phytoplankton to a diatom dominated community. Below an upper layer characterized by constant values, the $\tilde{b}_{\text {bp }}$ showed a rapid decrease to a broad minimum within the DCML. The higher values below the DCML are consistent with enhanced remineralization below the eddy-induced bloom. Both the "senescent" and the "healthy" diatom layers are characterized by similar optical properties, indicating
\end{abstract}

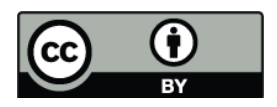

Correspondence to: F. Nencioli (francesco.nencioli@opl.ucsb.edu) some possible limitations in using optical measurements to fully characterize the composition of suspended material in the water column. The inverse relationship between $\tilde{b}_{\mathrm{bp}}$ and $[\mathrm{chl}] / c_{\mathrm{p}}$, reported by others for Case II waters, is observed neither for the background conditions, nor in the presence of the eddy-induced diatom bloom. Between the two parameters, only the backscattering ratio showed the potential to be a successful indicator for changes in particle composition in Case I waters.

\section{Introduction}

During the last two decades, many studies have focused on the relationships between optical properties and biogeochemical constituents (e.g., phytoplankton, sediment, dissolved matter) in order to develop rapid, continuous, in situ techniques for retrieving information such as the amount, type and composition of suspended material in the water column. Several optical parameters can now be used to obtain information on ocean living and non-living particles, both from in situ and remote sensing platforms. Chlorophyll fluorescence, beam attenuation coefficient $\left[c_{\mathrm{p}}, \mathrm{m}^{-1}\right]$, total particulate scattering $\left[b_{\mathrm{p}}, \mathrm{m}^{-1}\right]$, and particulate backscattering $\left[b_{\mathrm{bp}}, \mathrm{m}^{-1}\right]$ are the optical quantities of main interest in this study. The slope of the spectral attenuation coefficient $[\gamma]$ and the slope of the spectral absorption coefficient $\left[\left(a_{\mathrm{p}} 488-a_{\mathrm{p}} 532\right) /(488-532), \mathrm{m}^{-1} \mathrm{~nm}^{-1}\right]$ are also used in support of the interpretation of vertical profiles of those quantities.

The slope of spectral $c_{\mathrm{p}}, \gamma$, can be used to estimate the particle size distribution (PSD) slope $[\xi]$ through the relationship $\gamma \approx \xi-3$ (Boss et al., 2001b,a). Assuming a hyperbolic PSD (Junge-type model), $\xi$ describes the shape of the distribution: higher values of $\xi$ indicate a steep distribution, in which smaller particles dominate. As the value of $\xi$

Published by Copernicus Publications on behalf of the European Geosciences Union. 
decreases, the PSD becomes flatter, indicating an increasing abundance of larger sized particles and thus increasing mean particle size.

Eisner et al. (2003) showed that the slope of spectral $a_{\mathrm{p}}$ normalized by the absorption value at $676 \mathrm{~nm}\left[a_{\mathrm{p}} 676\right]$ is inversely proportional to the ratio of the concentration of photoprotective pigments and the concentration of photosynthetic pigments [PPC/PSC]. For this reason it can be used to retrieve information on the qualitative nature of a phytoplankton assemblage and on photoadaptation processes. PPC/PSC varies depending on the specific phytoplankton assemblage, and, for a given assemblage, it increases with higher light levels. The $a_{\mathrm{p}}$ slope is thus typically characterized by low values within the upper mixed layer, and by increasing values with depth.

Chlorophyll fluorescence and $c_{\mathrm{p}}$ have long been used to measure, respectively, total chlorophyll and total particulate organic carbon (POC) concentrations in open ocean (Case I) waters (e.g. Morel, 1988; Siegel et al., 1989). In the open ocean, these two quantities are not correlated, since different processes regulate their distributions throughout the water column (Kitchen and Zaneveld, 1990). POC concentrations depend on phytoplankton growth rate and losses; whereas chlorophyll concentrations are driven mainly by photoadaptation (i.e. the change of chlorophyll concentration per cell, in response to light level variations) (Fennel and Boss, 2003). The ratio between these two quantities [[chl] $\left./ c_{\mathrm{p}}\right]$ was used by Boss et al. (2004) to characterize suspended material in shallow coastal (Case II) waters, along with the backscattering ratio $\left[b_{\mathrm{bp}} / b_{\mathrm{p}}\right.$, herein $\left.\tilde{b}_{\mathrm{bp}}\right]$. Twardowski et al. (2001) showed that $\tilde{b}_{\mathrm{bp}}$ can be used as a proxy for the bulk refractive index of particles, which depends on the bulk particulate composition. Particle assemblages dominated by inorganic material are generally characterized by higher values of bulk refractive index, and thus higher values of $\tilde{b}_{\mathrm{bp}}$, whereas assemblages dominated by organic particles such as phytoplankton and dead cell material are characterized by lower values.

Results from Boss et al. (2004) confirmed $\tilde{b}_{\mathrm{bp}}$ to be an appropriate parameter for distinguishing particles with different composition. Moreover, a rough inverse relationship was found between $\tilde{b}_{\mathrm{bp}}$ and $[\mathrm{chl}] / c_{\mathrm{p}}$. Since an increase in detritus (organic or inorganic material) results in higher values of $c_{\mathrm{p}}$ without affecting [chl], this ratio roughly indicates the abundance of phytoplankton relative to the total particle concentration. Presumably, the higher the value of $[\mathrm{chl}] / c_{\mathrm{p}}$, the higher the phytoplankton contribution to the total particle composition, and therefore the lower the value of $\tilde{b}_{\mathrm{bp}}$. For this reason, $[\mathrm{chl}] / c_{\mathrm{p}}$ was proposed as an additional indicator for particle composition.

In this study we analyze vertical profiles of $\tilde{b}_{\mathrm{bp}}$ and $[\mathrm{chl}] / c_{\mathrm{p}}$ in the upper $200 \mathrm{~m}$ of the water column in oligotrophic, open ocean (Case I) waters. Few studies have focused on the vertical distribution of these properties to these depths in Case I waters (e.g. Twardowski et al., 2007), as most open ocean studies primarily investigate the spatial and temporal evolution of optical parameters in the very upper layer of the water column (e.g. Huot et al., 2008; Behrenfeld et al., 2005; Morel et al., 2007) due to its importance for remote sensing. Vertical profiles from outside cyclone Opal are compared to the ones collected at its core to test the sensitivity of the two parameters to the changes in biogeochemical characteristics and the shift in ecological community observed within the eddy.

Mesoscale features in the open ocean are considered to play an important role in the global carbon cycle, since eddyinduced phytoplankton blooms can locally enhance the biological pump, especially when the bloom is associated with a shift in the ecological community (McGillicuddy et al., 1998). Optical measurements could provide a way to retrieve informations on the ecological community within a given eddy, without the need of direct collection of water samples. Optical parameters capable of detecting phytoplankton community changes would allow the retrieval of fundamental insitu information on the ecological state of mesoscale eddies, which could greatly improve our understanding of their role in governing the global biogeochemical cycles.

\section{Background: biogeochemical characteristics of cyclone Opal}

The Hawaiian archipelago is located in the middle of the North Pacific subtropical gyre. This region is typically oligotrophic, with low nutrient concentrations in the euphotic zone. The low nutrient availability limits both phytoplankton biomass and primary productivity. The ecological community is typically dominated by small sized phytoplankton, mainly cyanobacteria and photosynthetic picoand nanoeukariotes (Campbell and Vaulot, 1993), and primary productivity is almost entirely sustained by recycled nutrients. Nutrient concentrations increase with depth within the seasonal thermocline, so that a deep chlorophyll maximum layer (DCML), characterized by concentrations between $0.2-0.4 \mathrm{mg} \mathrm{Chl} \mathrm{m}^{-3}$, typically occur at the base of the mixed layer, at about $110-130 \mathrm{~m}$ depth (Falkowski et al., 1991).

Due to the interaction of prevailing Trade Winds with the mountains of the Hawaiian Islands of Maui and Hawaii, cyclonic and anticyclonic mesoscale eddies frequently evolve in the lee of the Big Island of Hawaii (Patzert, 1969; Lumpkin, 1998; Chavanne et al., 2002; Dickey et al., 2008). Cyclonic eddies are biologically "productive" and can induce large variations in the biogeochemical characteristics of oligotrophic regions (Falkowski et al., 1991; McGillicuddy et al., 1998; McNeil et al., 1999). These eddies are characterized by a vertical uplift of the seasonal thermocline. Therefore these features display upwelling of deep, nutrient-rich waters into the euphotic zone. The increased nutrient availability can trigger an increase in primary productivity and a shift in the 


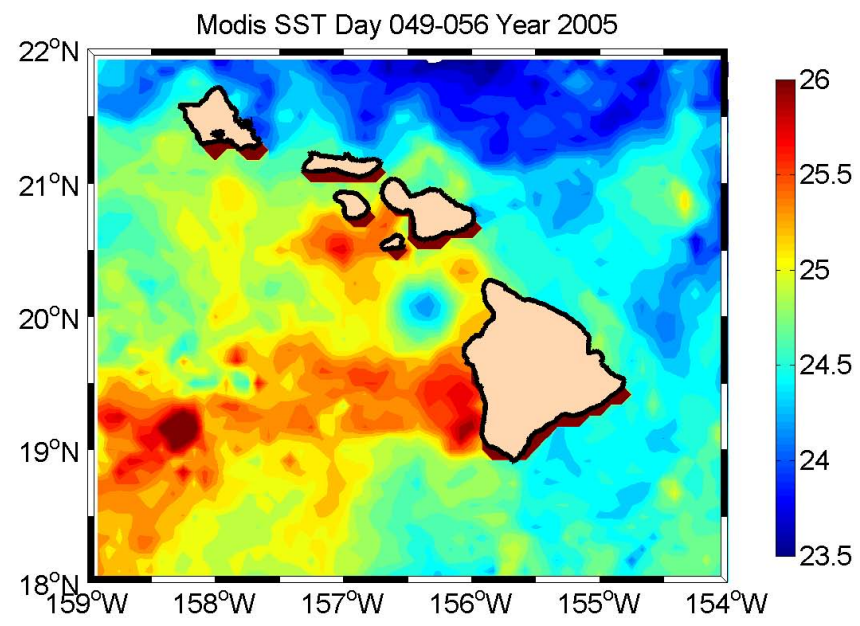

Fig. 1. Composite satellite SST image from the third week (18 to 25) of February 2005, evidencing cyclone Opal's cold core between the Big Island of Hawaii and the Island of Maui.

ecological community; thus cyclonic eddies are often characterized by phytoplankton blooms dominated by large size groups, such as diatoms.

The primary goal of the NSF-funded E-Flux project was to study the physical-biological interactions that occur within Hawaiian lee cyclonic eddies (Dickey et al., 2008). The third field experiment of the project (E-Flux III; 10-27 March, 2005; Benitez-Nelson et al., 2007; Dickey et al., 2008; Nencioli et al., 2008) focused on the cyclonic eddy, Opal, which first appeared in satellite Sea Surface Temperature (SST) imagery in the second half of February 2005 (Fig. 1). Cyclone Opal was intensively sampled over a 3-week period. During the first week of the field experiment a series of five transects were conducted across its center. The vertical profiles analyzed in this study were collected during the fourth transect (14 to 15 March ). Figure 2 shows the location of the four stations where the profiles were collected. The estimated position of the center of the eddy at the time of data collection is also indicated in Fig. 2. Vertical sections of velocity (not shown, see Nencioli et al., 2008) clearly reveal the cyclonic (anticlockwise) circulation associated with the eddy. Opal was a well-developed cyclonic eddy, characterized by intense doming of isopycnal surfaces, and enhanced chlorophyll concentrations at its center (Fig. 3). The DCML shoaled from $\approx 120$ to $\approx 70 \mathrm{~m}$ at the center of the eddy, where chlorophyll concentration reached its maximum values of $\approx 1 \mathrm{mg} \mathrm{Chl} \mathrm{m}{ }^{-3}$.

Water samples were collected during the third transect across the eddy center (13 to 14 March). Pigment and microscopy analyses of those samples revealed that the phytoplankton bloom within Opal was characterized by a shift in the ecological community (Rii et al., 2008; Brown et al., 2008). The DCML at the center of the eddy was in fact dominated by large diatoms, which accounted for almost $85 \%$ of

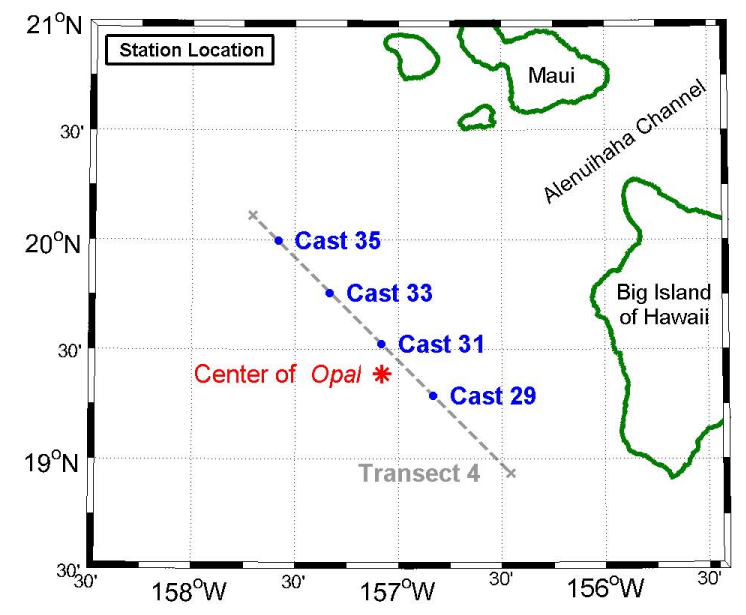

Fig. 2. Position of the four casts used in this study, and location of the estimated center of the eddy, Opal, at the time the casts were collected. The dashed line indicates the vertical section shown in Fig. 3. Notice that the position of the eddy center has changed from Fig. 1, due to Opal's migration (see Dickey et al., 2008; Nencioli et al., 2008).

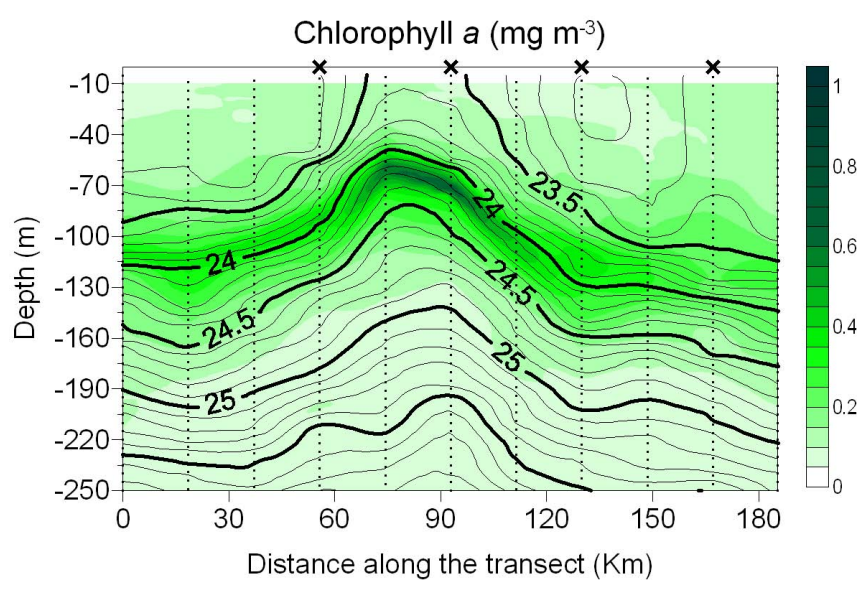

Fig. 3. Vertical section of chlorophyll concentration. The contourlines indicate isopycnal surfaces ( $\sigma_{t}$ values given). The black $X$ 's indicate the positions along the transect of the four casts discussed in this study. The small dots indicate the depths at which the data used to reconstruct the section were collected. The vertical section was reconstructed using all the vertical profiles available for the transect (see Nencioli et al., 2008)

the total phytoplankton biomass at Opal's core (Brown et al., 2008). Another important feature evidenced by microscopy analysis was the presence of a layer of "senescent" diatoms immediately above the "healthy" diatoms of the DCML at the center of the eddy. Up to $85 \%$ percent of the diatom frustules found in this layer were empty, lacking both chlorophyll and cytoplasm (Brown et al., 2008). At Opal's core, the water column can therefore be divided into four different regions, 
each one characterized by different biogeochemical conditions and ecological communities (Landry et al., 2008):

1. a surface mixed layer still dominated by small phytoplankton;

2. an intermediate layer characterized by "senescent" diatoms and high concentrations of empty frustules;

3. the DCML dominated by large, "healthy" diatoms;

4. and a deep layer below the DCML characterized by a decrease of phytoplankton concentrations with depth .

\section{Instrumentation and methods}

In-situ measurements of hydrographic and optical parameters were made with a ship deployed profiling package. Vertical profiles were performed at the four stations indicated in Fig. 2 down to a depth of $\sim 450 \mathrm{~m}$. A SeaBird Electronics 9/11+CTD was used to measure temperature, conductivity and depth. Chlorophyll concentrations and particle backscattering at $700 \mathrm{~nm}\left[b_{\mathrm{bp}}(700)\right]$ were measured with a WET Labs ECO-FLNTU fluorometer/turbidity sensor. Hyperspectral absorption and attenuation coefficients were measured at 84 different wavelengths between 400 and $730 \mathrm{~nm}$ (resolution of $\sim 4 \mathrm{~nm}$ ) with a WET Labs AC-S.

Since the profiling optics package was always deployed while attached to the ship profiling package, chlorophyll concentrations recorded by the ECO-FLNTU sensor were corrected using the concentrations measured by the ship fluorometer, obtained from calibrated fluorescence (see Nencioli et al., 2008). A strong linear relationship was found between the two $\left(r^{2}=0.95\right.$, not shown), so that chlorophyll concentrations were estimated using the relationship $[\mathrm{Chl}]=0.91 \mathrm{Chl}_{\mathrm{ECO}}+0.8$, where $\mathrm{Chl}_{\mathrm{ECO}}$ is the concentration recorded by the ECO-FLNTU sensor.

We obtained $b_{\mathrm{bp}}$ (700) data by processing total instrument counts from the ECO-FLNTU sensor; however values were unreasonably high. The origin of the problem was most likely an inaccurate calibration, which resulted in an incorrect scale factor used to convert instruments counts into $b_{\mathrm{bp}}$. In order to retrieve correct $b_{\mathrm{bp}}$ values from the FLNTU measurements, an alternative scaling factor was derived using the instrument counts at depths $>400 \mathrm{~m}$. Absorption and attenuation coefficients measured at those depths are similar in magnitude to those observed in the eastern South Pacific Ocean in extremely clear waters (Twardowski et al., 2007). In clear waters, the backscattering from pure seawater $\left[b_{\mathrm{bsw}}\right]$ accounts for 90 to $95 \%$ of the total backscattering [b $b_{\mathrm{b}}$, so that $b_{b} \approx 1.05 b_{\mathrm{bsw}}$ (Twardowski et al., 2007). Using the method of Twardowski et al. (2007), based on the work of Morel (1974) and Buiteveld et al. (1994), it was possible to derive values of $b_{\text {bsw }}$ at $700 \mathrm{~nm}$ below $400 \mathrm{~m}$ from measured temperature and salinity data, and then $b_{\mathrm{b}}$. Since both instrument counts and $b_{\mathrm{b}}(700)$ were fairly constant below
$400 \mathrm{~m}$, the new scaling factor was simply computed as the average ratio between the two. FLNTU measurements were converted into $b_{\mathrm{b}}(700)$ throughout the entire water column using the newly derived scaling factor. These values were then corrected by $b_{\text {bsw }}$ (700) computed at each depth again, to obtain $b_{\text {bp }}(700)$. Assuming $a_{\mathrm{p}}(700) \approx 0$ (e.g. Bricaud and Stramski, 1990; Babin and Stramski, 2002), $b_{\mathrm{p}}$ (700) was simply equal to $c_{\mathrm{p}}$ (700). The values of $b_{\mathrm{p}}(700)$ and $b_{\mathrm{bp}}(700)$ were used to derive $\tilde{b}_{\mathrm{bp}}$.

Hyperspectral absorption and attenuation coefficients included the contributions by all in-water constituents except water: $a_{\mathrm{pg}}(\lambda)=a_{\mathrm{p}}(\lambda)+a_{\mathrm{g}}(\lambda)$, and $c_{\mathrm{pg}}(\lambda)=c_{\mathrm{p}}(\lambda)+$ $a_{\mathrm{g}}(\lambda)$, where $a_{\mathrm{p}}$ and $c_{\mathrm{p}}$ represent the absorption and total attenuation contributions due to particulate material and $a_{\mathrm{g}}$ is the absorption contribution to total beam attenuation coefficient due to dissolved material (scattering by dissolved material is negligible, i.e. $b_{\mathrm{g}}=0$ ). AC-S data were corrected for temperature and salinity effects using the coefficients derived by Sullivan et al. (2006). After this correction, the Zaneveld et al. (1994) proportional method was applied in order to correct for the scattering errors in the absorption measurements.

Values of the spectral slope of beam attenuation $[\gamma]$ at different depths were computed from the $c_{\mathrm{p}}$ spectra using the relationship

$c_{\mathrm{p}}(\lambda)=A_{c} \lambda^{-\gamma}$

where $A_{c}$ is the amplitude of the spectrum, $\lambda$ is wavelength and $\gamma$ is the hyperbolic exponent (e.g. Boss et al., 2001b; Twardowski et al., 2001). The spectral slope was computed only for the vertical profile collected at Opal's center (Cast 31).

Since $a_{\mathrm{g}}$ was not measured directly, vertical profiles of spectral chromomorphic organic dissolved matter (CDOM) absorption $\left[a_{\mathrm{g}}(\lambda)\right]$ had to be reconstructed, in order to obtain $c_{\mathrm{p}}(\lambda)$ from the measured $c_{\mathrm{pg}}(\lambda)$ as $c_{\mathrm{p}}(\lambda)=c_{\mathrm{pg}}(\lambda)-a_{\mathrm{g}}(\lambda)$. CDOM absorption spectra at a given depth has been found to follow the spectral law

$a_{\mathrm{g}}(\lambda)=a_{\mathrm{g}}\left(\lambda_{0}\right) \exp \left[-s\left(\lambda-\lambda_{0}\right)\right]$

where $\lambda_{0}$ is a reference wavelength (Bricaud et al., 1981). Knowing the vertical profiles of $a_{\mathrm{g}}\left(\lambda_{0}\right)$ and the exponential coefficient $s$, it is thus possible to use Eq. 2 to reconstruct the vertical profiles of $a_{\mathrm{g}}(\lambda)$.

In recent years an increasing number of studies have investigated the spatial and vertical distribution of CDOM in the world oceans (e.g. Siegel et al., 2002; Nelson et al., 2007; Yamashita and Tanoue, 2009). Surface values of $a_{\mathrm{g}}$ (440) from the Hawaiian Ocean Time-Series (HOT) are presented in Siegel et al. (2002). The time series is characterized by low variability, and the average value is around 0.006$0.007 \mathrm{~m}^{-1} ; a_{\mathrm{g}}(440)$ was found to contribute between 40 to $50 \%$ to the total $a_{\mathrm{pg}}(440)$. In our dataset the average value of $a_{\mathrm{pg}}$ (440) within the upper $20 \mathrm{~m}$ of the water column is $\approx 0.013$. Therefore, we considered appropriate a surface 
value of $0.006 \mathrm{~m}^{-1}$. Vertical profiles of $a_{\mathrm{g}}$ (320) from the Sargasso Sea are described in Nelson et al. (2007). Values are fairly constant in the upper mixed layer, where they are low due to photobleaching; below the mixed layer, they increase to the depth of the DCML where they reach their maxima; further down, they decrease again to values in between the two extremes, and remain roughly uniform throughout the deep ocean. A similar profile was observed in the subtropical Pacific Ocean by Yamashita and Tanoue (2009). Vertical profiles of the exponential coefficient $s$ were also presented: its values are roughly constant with depth in the deep ocean, whereas they increase within the upper mixed layer because of photobleaching. Values of $a_{\mathrm{g}}(440)$ for the DCML and the deep ocean were obtained using Eq. 2 and the $a_{\mathrm{g}}(320)$ and $s$ values from Yamashita and Tanoue (2009): they were 0.020 and $0.016 \mathrm{~m}^{-1}$ respectively. Surface values obtained using this procedure were in agreement with the ones we adopted from Siegel et al. (2002).

The resulting vertical profile of $a_{\mathrm{g}}$ (440) is shown in the upper panel of Fig. 4. Surface values are assumed constant down to the base of the surface mixed layer, (computed as the depth at which the seawater temperature is $1^{\circ}$ less than at $10 \mathrm{~m}$ depth; see also Benitez-Nelson et al., 2007); there $a_{\mathrm{g}}$ (440) increases until it reaches the depth of the DCML (depth of the maximum chlorophyll concentration); after the DCML, it decreases down to its deep value, and then remains constant with depth. The increase at the bottom of the upper mixed layer and the decrease after the DCML depth are parametrized by a Gaussian curve. The parameter $s$ is assumed to be constant within the upper mixed layer, and to linearly decrease to its deep value from the base to the mixed layer down to the depth where $a_{\mathrm{g}}$ (440) reaches its deep value. Values of $s$ reported by Yamashita and Tanoue (2009) were obtained for spectra centered at shorter wavelengths than ours. Since $s$ is not constant in the entire spectral range $(300-600 \mathrm{~nm})$ it is possible that those values are slightly higher than the ones for longer wavelengths (Twardowski et al., 2004). This might lead to an underestimate of the values of $a_{\mathrm{g}}(\lambda)$ within the wavelength range used to compute the values of $\gamma$. We therefore decided to use lower values of $s$, as obtained by Morel et al. (2007) for open ocean waters in the tropical South Pacific: surface values of $s$ were assumed to be 0.02 , whereas its deep value was taken to be 0.015 . The bottom panel in Fig. 4 shows average spectral values of measured $a_{\mathrm{pg}}$, reconstructed $a_{\mathrm{g}}$ and $a_{\mathrm{p}}$ (computed as the difference between the two) for a $10 \mathrm{~m}$ depth interval across the DCML depth. The resulting $a_{\mathrm{p}}$ spectra is similar to the ones observed in other studies (e.g. Eisner et al., 2003), with values that become roughly constant below $450 \mathrm{~nm}$. This can be used as a further indication that the maximum $a_{\mathrm{g}}$ value adopted for the DCML depth is appropriate.
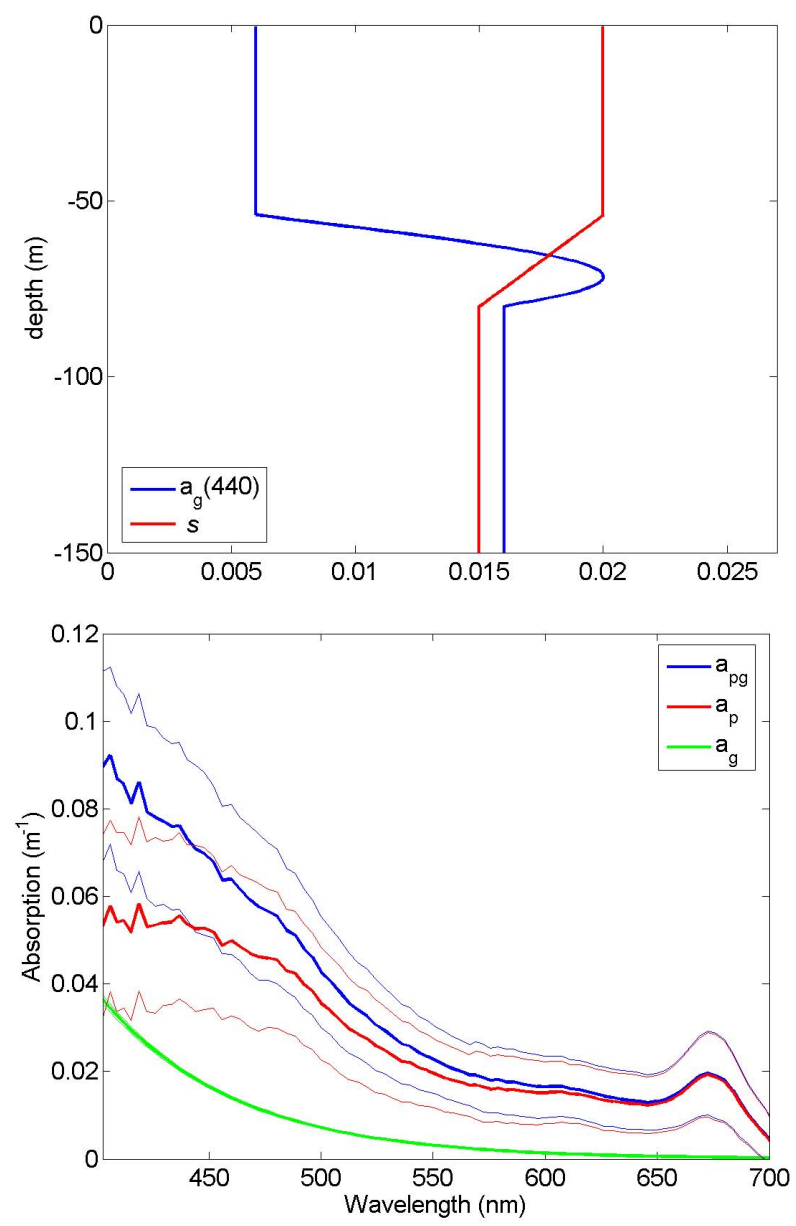

Fig. 4. (top) Vertical profiles of CDOM absorption at $440 \mathrm{~nm}$ $\left[a_{\mathrm{g}}(440)\right]$ and the exponential coefficient $s$, used to reconstruct the vertical distribution of $a_{\mathrm{g}}(\lambda)$ using Eq. 2; (bottom) Average spectra of measured total absorption $\left[a_{\mathrm{pg}}\right]$, reconstructed CDOM absorption $\left[a_{\mathrm{g}}\right]$, and derived particle absorption $\left[a_{\mathrm{p}}\right]$ within the DCML (thinner lines indicate the one standard deviation inteval).

Particle attenuation spectra $\left[c_{\mathrm{p}}(\lambda)\right]$ were computed at each depth by subtracting the reconstructed CDOM absorption spectra $\left[a_{\mathrm{g}}(\lambda)\right]$ from the measured total attenuation spectra $\left[c_{\mathrm{pg}}(\lambda)\right]$, and the spectral slopes $[\gamma]$ were then computed. The effects of this correction to the values of $\gamma$ will be discussed in more detail in the next section (see discussion of Fig. 11). Since measured attenuation coefficients at wavelengths $>600 \mathrm{~nm}$ are small (comparable to the background noise), only wavelengths from 400 to $600 \mathrm{~nm}$ (a total of 54 wavelengths) were used for the spectral fit of $c_{\mathrm{p}}$. Once values of $\gamma$ were computed, values of $c_{\mathrm{p}}$ at specific wavelengths could be obtained using Eq. 1. Following Boss et al. (2004), attenuation coefficients at $650 \mathrm{~nm}\left[c_{\mathrm{p}}(650)\right]$ were used to compute $[\mathrm{chl}] / c_{\mathrm{p}}$. All data were averaged using $0.5 \mathrm{~m}$ bins. 


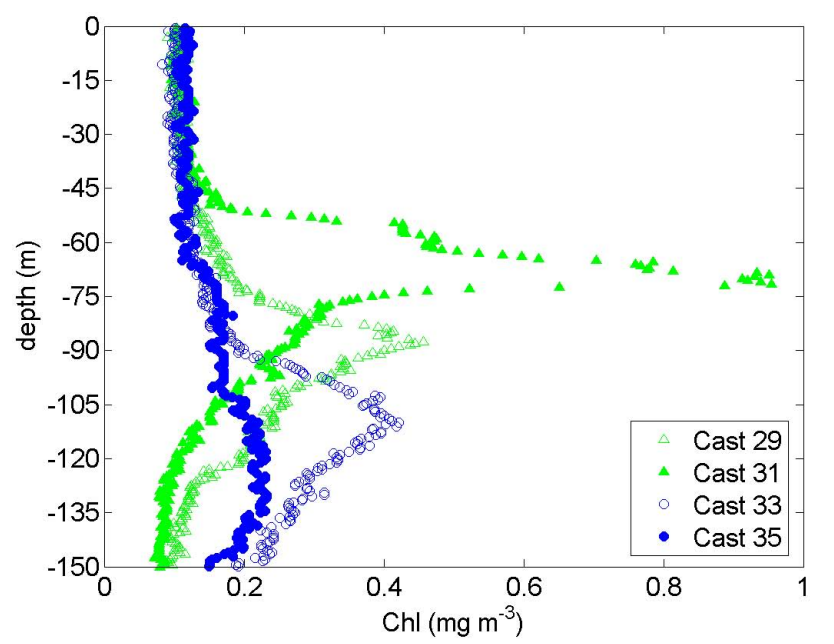

Fig. 5. Vertical profiles of chlorophyll concentration for the four casts.

\section{Results}

Figure 5 shows vertical profiles of chlorophyll concentration for the four stations from Fig. 2. All profiles are characterized by similar surface concentrations, a DCML, and a decrease in concentrations to values close to the fluorometer detection limit below the DCM. The distance of each sampling station from Opal's center varied (see Fig. 2), with Cast 35 being the furthest, and Cast 31 the closest. The four profiles display what is shown in the vertical section in Fig. 3, namely evidence of a shoaling of the DCML toward Opal's core, which is in conformance with the isopycnal uplift associated with the eddy. At the same time, chlorophyll concentrations increase due to the higher nutrient availability in the euphotic zone. Cast 35 shows a broad DCML at about $120 \mathrm{~m}$ depth, with chlorophyll concentrations up to $0.2 \mathrm{mg} \mathrm{Chl} \mathrm{m}^{-3}$. These conditions are typical of the Hawaiian region (e.g. Falkowski et al., 1991), so that Cast 35 can be considered representative of the background conditions outside the influence of Opal. On the other hand, Cast 31 can be assumed representative of the eddy-induced diatom bloom conditions. The DCML is located at about $70 \mathrm{~m}$ depth, $50 \mathrm{~m}$ shallower than in Cast 35 . Chlorophyll concentrations show a 5-fold increase, reaching maximum values of the order of about $1 \mathrm{mg} \mathrm{Chl} \mathrm{m}^{-3}$, indicating the presence of a phytoplankton bloom at the center of the eddy. The DCML in Cast 31 is sharper than the one in Cast 35. Chlorophyll concentrations increase and decrease quite rapidly with depth, so that the layer of the DCML, characterized by chlorophyll concentrations $>0.5 \mathrm{mg} \mathrm{Chl} \mathrm{m}^{-3}$, is only $\sim 10 \mathrm{~m}$ thick.

Vertical plots of $c_{\mathrm{p}}(650)$ are shown in Fig. 6. Surface values vary between 0.03 and $0.04 \mathrm{~m}^{-1}$, whereas values at depth are very low for the four casts. Similar to the peaks in chlorophyll concentration in Fig. 5, the peaks in particle attenuation

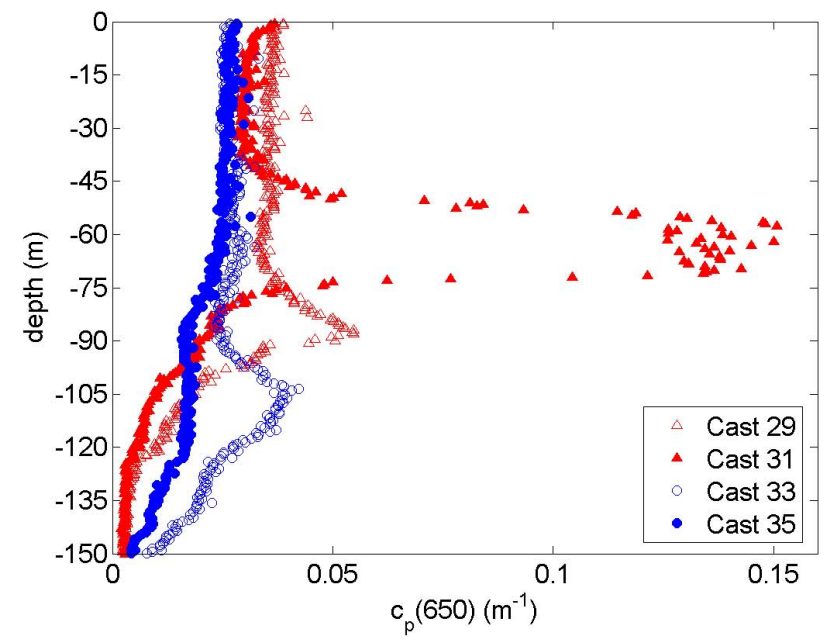

Fig. 6. Vertical profiles of attenuation coefficient for the four casts.

become shallower, and increase in magnitude towards Opal's center. However, further comparison with Fig. 5 shows that for each profile the maximum value of $c_{\mathrm{p}}$ (650) occurs a few meters above the DCML. This is a common feature in oligotrophic regions (e.g. Kitchen and Zaneveld, 1990; Fennel and Boss, 2003; Boss et al., 2007). In fact, POC and chlorophyll maxima are regulated by different mechanisms: the former occur where phytoplankton grow rates are balanced by losses, whereas the latter are determined by photoadaptation (i.e. the change of chlorophyll concentration per cell, in response to light level variations) and, to a lesser extent, by nutrient availability (Fennel and Boss, 2003). The $c_{\mathrm{p}}$ (650) profile from Cast 35 does not reveal any maximum associated with the DCML. Cast 31, on the other hand, is characterized by a $c_{\mathrm{p}}(650)$ maximum broader than the corresponding peak in chlorophyll concentration. Both maxima quickly decay below $70 \mathrm{~m}$, but the peak in particle attenuation extends to shallower depths (roughly up to $50 \mathrm{~m}$ ).

No water samples were collected during the fourth transect of the experiment, when the optics package was deployed. For this reason it is not possible to directly correlate the measured optical properties to values of quantities such as pigment concentrations, total organic carbon or total suspended matter. However analyses of the water samples collected during the third transect, allowed for the detailed characterization of the four different ecological communities alternating throughput the water column at Opal's core as described at the end of the previous section. The same four regions can be identified within the vertical profile of the center cast from the fourth transect, Cast 31 (Fig. 7). The first region extends throughout the surface layer and therefore its lower boundary is represented by the depth of the upper mixed layer (already computed to reconstruct the vertical profile of $\left.a_{\mathrm{g}}(440)\right)$. The DCML is characterized by the highest chlorophyll concentrations (in our case $>0.5 \mathrm{mg} \mathrm{Chl} \mathrm{m}^{-3}$ ). The limits of these two 


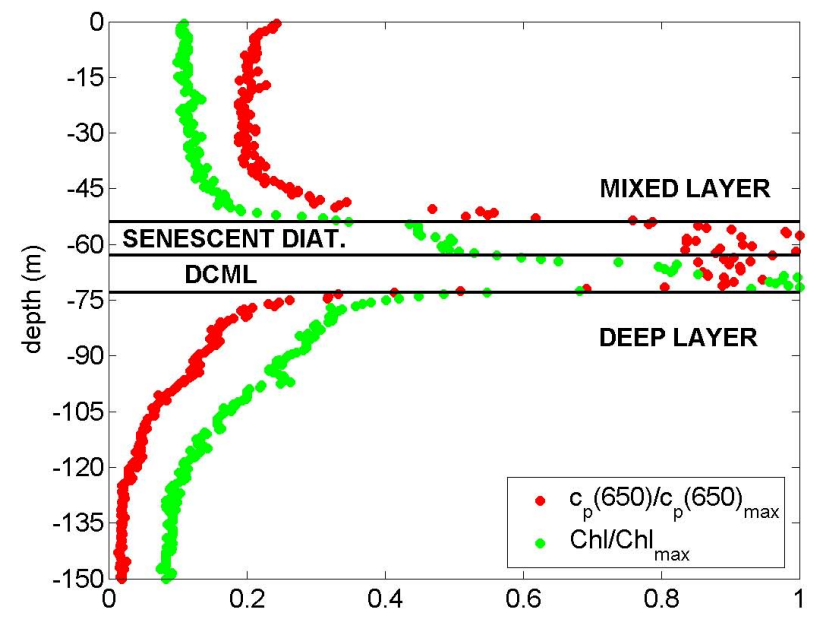

Fig. 7. Vertical profiles of normalized chlorophyll concentration and particle attenuation used to identify the four ecological regions observed at Opal's center. The two quantities were normalized by their maxima to scale them to a common range of values. The three black lines indicate respectively (shallower to deeper): depth of the upper mixed layer; top of the DCML; bottom of the DCML. They will be also used in Figs. 8, 10 and 11 to provide better evidence of the sensitivity of the different optical parameters to the observed changes in particle size and composition.

regions automatically define the other two: the deep layer extends from below the bottom of the DCML to the deep ocean, whereas the intermediate layer extends from the bottom of the upper mixed layer to the top of the DCML.

These limits represent only a rough estimate of the depth extent of the four ecological regions; nonetheless, they provide a framework that contributes to a better interpretation of the optical measurements: for instance, from Fig. 7, the observed broader peak in $c_{\mathrm{p}}$, a good proxy for particle concentration, can be attributed to the presence of the layer of "senescent" diatoms above the DCML at the center of Opal. The limits of the four regions identified for Cast 31 will be shown in Figs. 8, 10, and 11, and they will be used to infer the sensitivity of the optical parameters to the variations in particle size and composition observed at Opal's center. The biogeochemical characteristics at Opal's center are remarkably different from the typical open ocean conditions observed outside the eddy. In particular, the shift in the ecological community from small to large sized phytoplankton, and the intermediate layer dominated by large concentrations of empty diatom frustules might substantially alter the vertical profiles of certain optical parameters. Those parameters that show well defined features associated with the four regions represent an important proxy for the study of physicalbiogeochemical interactions within mesoscale eddies, as well as biogeochemical cycles in general, in open ocean. In fact, they would allow the retrieval of information concerning the biogeochemical state of the water column without the need of water sample collection and analyses.

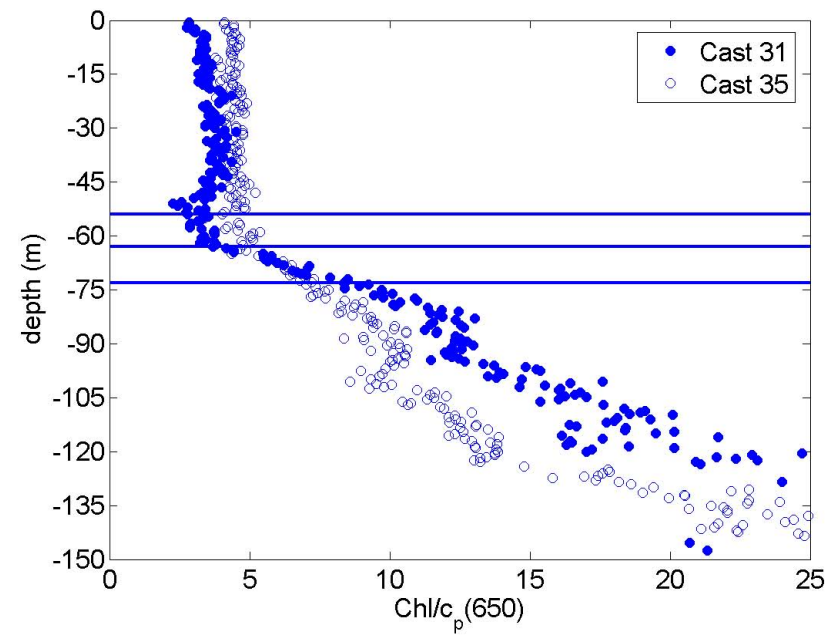

Fig. 8. Vertical profiles of [chl] $/ c_{\mathrm{p}}$ for Casts 31 and 35 .

Figure 8 shows vertical plots of $[\mathrm{chl}] / c_{\mathrm{p}}$ for Cast 35 and Cast 31 (the other two casts representing only intermediate conditions between these two). The profile from Cast 35 is characterized by constant values within the upper layer, and a gradual increase between $60 \mathrm{~m}$ and $150 \mathrm{~m}$ depth. The ratio between chlorophyll concentration and attenuation coefficient can vary depending on several factors. Among these, the proportion between mineral and living particles, the size distribution, photoadaptation, and phytoplankton composition are considered to be the most important (Boss et al., 2004). Since small sized phytoplankton dominate the ecological community outside the eddy throughout the whole water column, the variation of $[\mathrm{chl}] / c_{\mathrm{p}}$ with depth observed in Cast 35 is likely attributable to photoadaptation. More specifically, the values increase with depth because chlorophyll concentration per cell increases as phytoplankton experience decreasing light levels. As already remarked, this is a common feature in open ocean waters characterized by strong stratification (Kitchen and Zaneveld, 1990).

Despite the different biogeochemical characteristics observed at Opal's center, the vertical profile of $[\mathrm{chl}] / c_{\mathrm{p}}$ for Cast 31 is characterized by the same features observed for Cast 35. Values are roughly constant in the upper mixed layer, whereas they gradually increase with depth below it. The only two differences are represented by the minimum observed at the base of the mixed layer, and by the steeper increase towards high values below the DCML. The minimum is an indication of the beginning of the intermediate layer, where $c_{\mathrm{p}}$ (650) rapidly increases due to the increasing concentrations of empty frustules and "senescent" diatoms, whereas chlorophyll remains relatively low. However, as chlorophyll concentrations start to increase at the bottom of the mixed layer, the ratio immediately starts to grow. This indicates that photoadaptation remains the main controlling factor for $[\mathrm{chl}] / c_{\mathrm{p}}$ within the intermediate 


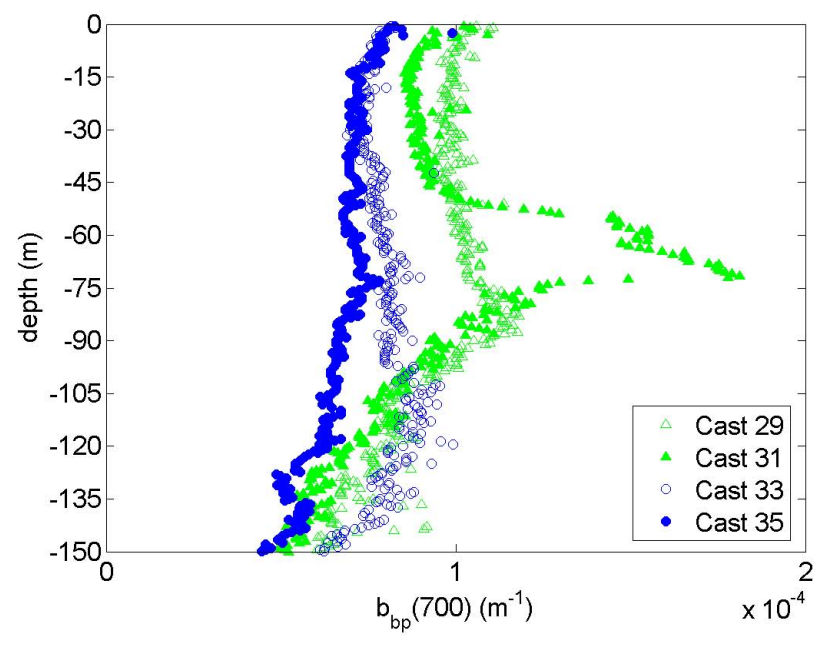

Fig. 9. Vertical profiles of $b_{\mathrm{bp}}(700)$ for the four casts.

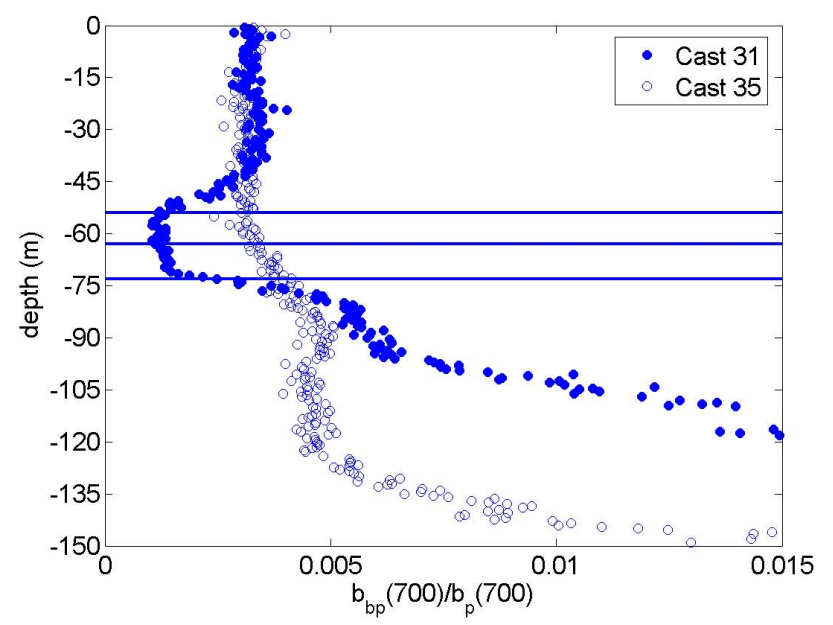

Fig. 10. Vertical profiles of $\tilde{b}_{\mathrm{bp}}$ for Cast 31 and Cast 35 .

layer (relatively high concentrations of non-photosynthetic particles, although biogenic), as well as within the DCML (change in phytoplankton composition from small size cells to diatoms). The steeper increase most likely results from the combination of photoadaptation with another process serving as a controlling factor for $[\mathrm{chl}] / c_{\mathrm{p}}$ : remineralization. It is possible that as phytoplankton are degraded or mineralized (this is consistent with the decreasing values of $c_{\mathrm{p}}(650)$ below the DCML), some of the chlorophyll might escape from broken cells into the water column in the form of chlorophyll and rapidly produced detrital phaeopigment. This could explain why chlorophyll fluorescence (including phaeopigment) remain much higher, despite lower $c_{\mathrm{p}}(650)$ values between 80 and $110 \mathrm{~m}$ compared to the values at the surface.

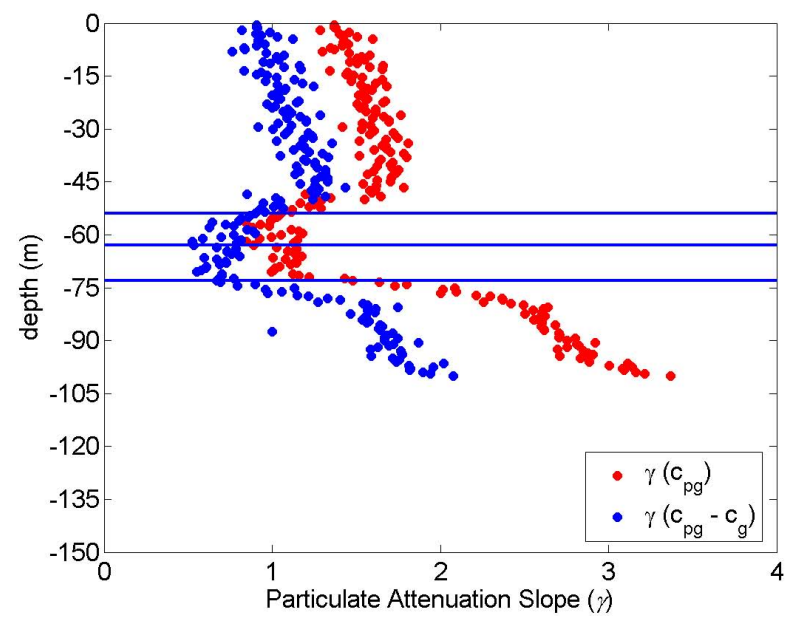

Fig. 11. Vertical profiles of PSD slope $[\gamma]$ computed using the measured $c_{\mathrm{pg}}$ (red), and the corrected $c_{\mathrm{p}}$ (blue), for Cast 31 .

Profiles of $b_{\mathrm{bp}}$ (700) are shown in Fig. 9. The values at the surface are on the same order of magnitude as found by Huot et al. (2007), indicating that the method we developed to derive particle backscattering values from the ECOFLNTU counts appears reasonable. The profile from Cast 31 resembles the chlorophyll profile, showing a sharp peak that reaches its maximum value at about $70 \mathrm{~m}$ depth. On the other hand, Cast 35 is more similar to the $c_{\mathrm{p}}$ (650) profile; $b_{\mathrm{bp}}(700)$ does not show a maximum occurring at the depth of the broad DCML. For all four casts, vertical profiles of $c_{\mathrm{p}}(700)$ show similar features as $c_{\mathrm{p}}(650)$, but slightly lower values (not shown).

Figure 10 shows the vertical profiles of $\tilde{b}_{\mathrm{bp}}$ for Cast 31 and 35. Values at the surface are on the same order of magnitudes as previous observations in the open ocean (Twardowski et al., 2007; Huot et al., 2008). The vertical profile for Cast 35 is characterized by roughly constant values of $\tilde{b}_{\text {bp }}$ down to a depth of $\sim 60 \mathrm{~m}$. Between 60 and $90 \mathrm{~m}$ depths, the ratio slowly increases, reaching slightly higher values between 90 and $120 \mathrm{~m}$ depths. The similar values between the two layers indicate that the particle population was dominated by small sized phytoplankton, other water-filled organisms and detritus throughout the water column. The presence of small phytoplankton was confirmed by microscopic analysis of the water samples collected outside the eddy during the third transect of the experiment. Nonetheless, the slightly higher values between 90 and $120 \mathrm{~m}$ depth might indicate a shift from surface to depth adapted species. Below $120 \mathrm{~m}$, the backscattering ratio increases noticeably, indicating a shift toward smaller and/or possibly harder (i.e. higher bulk refractive index) material. This is an indication of remineralization occurring below the DCML. 
Unlike [chl] $/ c_{\mathrm{p}}$, the vertical profile of $\tilde{b}_{\mathrm{bp}}$ for Cast 31 is noticeably different than the profile for Cast 35 . The most important feature is the broad minimum between 53 and $74 \mathrm{~m}$. As indicated by the lines defining the limits of the four ecological regions, this is related to the shift from small to large sized phytoplankton observed at the center of the eddy, but may also be influenced by living cells with high relative water content (i.e, lower refractive index) being more dominant here relative to the surrounding water column. Even for this cast, the increase in values below the DCML can be interpreted as the result of phytoplankton degradation. This supports our hypothesis that remineralization is an additional factor determining the steeper increase in $[\mathrm{chl}] / c_{\mathrm{p}}$ below the DCML.

The vertical profile of $\gamma$ can be used as an indicator to further confirm that the minimum in $\tilde{b}_{\mathrm{bp}}$ in Cast 31 reflects the observed shift in community at Opal's core. The two profiles shown in Fig. 11 are both for Cast 31, and represent the values of gamma derived using the measured $c_{\mathrm{pg}}(\lambda)$, and for $c_{\mathrm{p}}(\lambda)=c_{\mathrm{pg}}(\lambda)-a_{\mathrm{g}}(\lambda)$, where $a_{\mathrm{g}}(\lambda)$ is the reconstructed CDOM absorption spectra. Comparison of the two plots shows that the correction for $a_{\mathrm{g}}$, while reducing the values of $\gamma$ throughout the water column, does not affect the overall shape of the profile. This indicates that the qualitative interpretation of the vertical profile is independent from the reconstructed profile of the spectral $a_{\mathrm{g}}$. The values in the upper layer are comparable to the ones observed in previous studies (Twardowski et al., 2001; Boss et al., 2001b). As expected, between 53 and $74 \mathrm{~m}$ depths (from the bottom of the mixed layer to the bottom of the DCML) the profile shows a broad minimum. This indicates an increase in the mean particle size of the suspended material in that layer, and is compatible with the diatom-dominated phytoplankton bloom observed at the center of the eddy. Values of $\gamma$ are plotted only down to $100 \mathrm{~m}$ depth. Below that depth, $\gamma$ becomes unreasonably high. The accuracy of our estimate of the spectral slope is most likely affected by the low $c_{\mathrm{p}}$ values measured in the very clear deep waters. This results in a low signal-to-noise ratio, which does not allow the resolution of the spectrum to be accurate enough to obtain a good estimate of $\gamma$. Increasing uncertainty in the $a_{\mathrm{g}}(\lambda)$ correction might also play an important role.

Another parameter, which has been found to be sensitive to photoadaptation and change in phytoplankton composition, is the absorption spectral slope proposed by Eisner et al. (2003). The parameter was tested for our dataset (not shown). Measured $a_{\mathrm{pg}}(\lambda)$ values were corrected by the reconstructed $a_{\mathrm{g}}(\lambda)$ profiles to obtain $a_{\mathrm{p}}(\lambda)$. The vertical profile of $a_{\mathrm{p}}$ slope for Cast 31 follows the expected shape: values are highly negative at the surface and they decrease between the bottom of the upper mixed layer and the bottom of the DCML. This is consistent with higher protective to photosynthetic pigment ratios at surface, and possibly supports a change in community structure with depth. However, without quantitative estimates of pigment concentrations, it is hard to quantify the contributions of the two separately. The values of the $a_{\mathrm{p}}$ slope however are out of the range of Eisner et al. (2003), their absolute values being much higher. This could be due to the different area of study between the two works. Without the support of direct measurements from water samples, this limits the interpretation of the vertical distribution of the $a_{\mathrm{p}}$ slope, since we would have to assume that the proposed relationship can be extrapolated outside the range measured by Eisner et al. (2003). The proposed normalization of the $a_{\mathrm{p}}$ slope by $a_{\mathrm{p}}$ (676) might also be responsible for the higher values obtained from our dataset. In fact, due to the low chlorophyll concentrations, $a_{\mathrm{g}}$ (676) is relatively low throughout the water column except within the DCML. This also reduces the signal-to-noise ratio, increasing the noise associated with $a_{\mathrm{p}}$ slope, particularly for the outer casts where chlorophyll concentrations are particularly low. Normalizing for $a_{\mathrm{p}}$ (676) is most likely not ideal for open ocean condition, and a different formulation for the $a_{\mathrm{p}}$ slope might be required in those regions.

\section{Conclusions}

The vertical distributions of the optical properties collected during the E-Flux III field experiment are clearly influenced by the presence of cyclone Opal. The isopycnal uplift and the phytoplankton bloom associated with the eddy result in a shoaling and an increase in magnitude of the peaks in chlorophyll concentration, $c_{\mathrm{p}}(650)$ and $b_{\mathrm{bp}}(700)$ from outside towards the center of the feature. The vertical profiles of chlorophyll and particle attenuation can be used to localize the depth ranges of the four ecological layers observed from the analyses of water sample collected during a previous transect. Near the center of the eddy, the surface layer extends from the surface to the depth of the upper mixed layer ( $\approx 53 \mathrm{~m}$ depth), where both $c_{\mathrm{p}}(650)$ and chlorophyll concentration begin to increase. The depth interval from the bottom of the upper mixed layer and the bottom of the DCML ( $\approx 53$ to $\approx 74 \mathrm{~m}$ depth) is characterized by high concentrations of diatoms, as confirmed by the vertical profile of $\gamma$. This layer can be further divided into the "senescent" diatom layer and the DCML. The first extends from the bottom of the upper mixed layer to the top of the DCML $(\approx 53$ to $\approx 63 \mathrm{~m}$ depth) and is characterized by increasing chlorophyll concentrations, and a $c_{\mathrm{p}}(650)$ value that has already reached its maximum. The second layer encompasses water depths of $\approx 63$ to $\approx 74 \mathrm{~m}$, where chlorophyll concentrations reach their maximum values.

According to our results, $[\mathrm{chl}] / c_{\mathrm{p}}$ is not a good indicator for particle composition changes in the water column in Case I water, either in the case of background conditions, or in the presence of the eddy-induced phytoplankton bloom. The main factor controlling the variation of this ratio with depth is likely photoadaptation and not the bulk particle composition as observed in shallow coastal waters (Boss et al., 2004). 

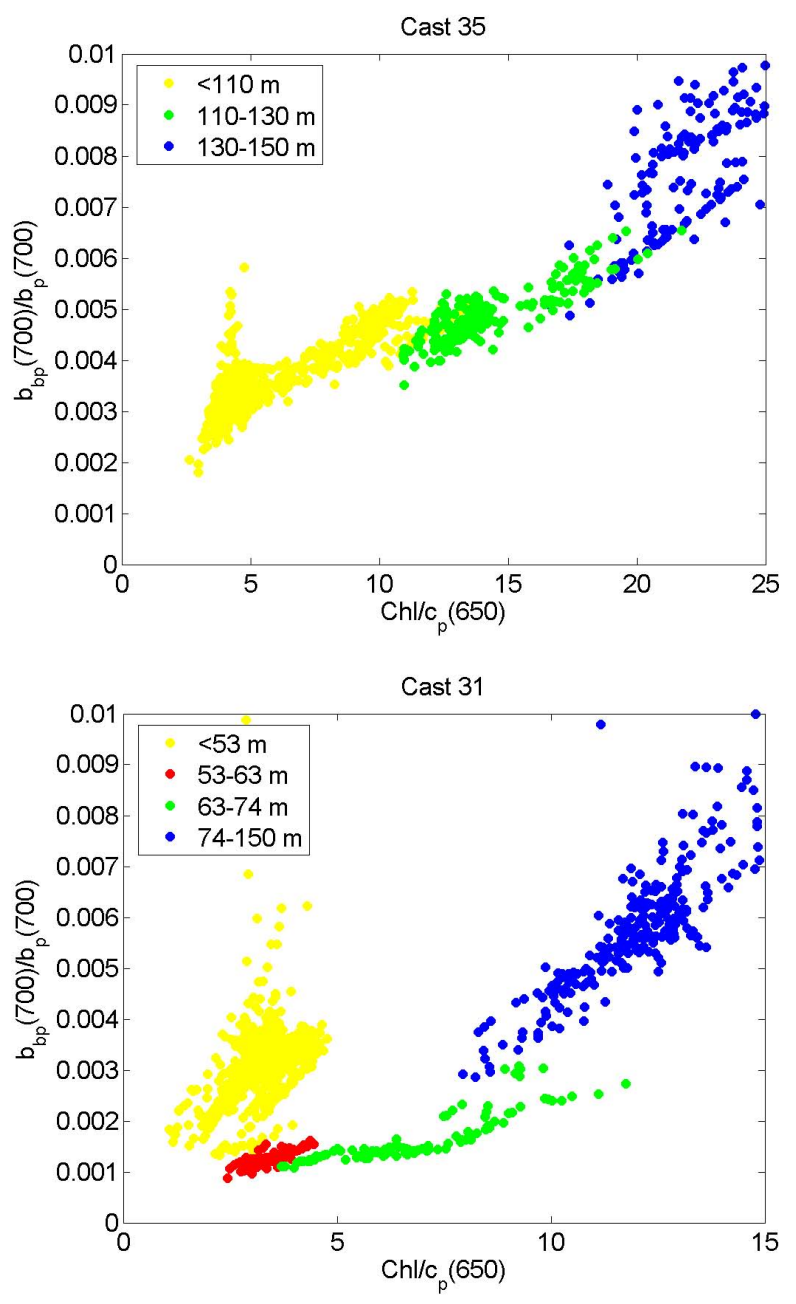

Fig. 12. Scatter plot of $\tilde{b}_{b p}$ versus [chl] $/ c_{\mathrm{p}}$ for Casts 35 (top) and 31 (bottom). The data shown are not binned, and they are grouped (using color coding) into four different depth intervals corresponding to distinct ecological communities.

Even in the presence of a diatom bloom as in Cast 31, the signal in $[\mathrm{chl}] / c_{\mathrm{p}}$ resulting from the shift in ecological community is completely lost due to the large increase caused by photoadaptation (except for few meters at the bottom of the upper mixed layer). The resulting profile is analogous to the one from Cast 35. Below the DCML remineralization might also be an important factor in regulating $[\mathrm{chl}] / c_{\mathrm{p}}$.

$\tilde{b}_{\mathrm{bp}}$ and $\gamma$ are better indicators for the bulk particle composition, and the vertical profiles of the two quantities show similar features. $\tilde{b}_{\mathrm{bp}}$ is nearly constant throughout Cast 35 , indicating no variation in the ecological community outside the eddy. Its increase below the DCML is consistent with intense remineralization processes. For Cast 31 , at the center of the eddy, $\tilde{b}_{\mathrm{bp}}$ clearly indicates the position of the layer with increased diatom concentrations between $\approx 53$ and $\approx 74 \mathrm{~m}$ depth. According to the $\tilde{b}_{\mathrm{bp}}$ profile, the water column can be divided into three distinct layers: a surface layer with small sized phytoplankton, a diatom-dominated middle layer, and a deep layer characterized by high remineralization. Unfortunately, for both $\tilde{b}_{\mathrm{bp}}$ and $\gamma$, it is not possible to further divide the middle layer into a "senescent" and a "healthy" diatom layer. The two layers do not seem to be characterized by distinct optical features, indicating some limitations on the information on particle composition that can be retrieved from optical measurements.

Finally, our data do not confirm the inverse relationship between $\tilde{b}_{\mathrm{bp}}$ and $[\mathrm{chl}] / c_{\mathrm{p}}$ found by Boss et al. (2004) for shallow coastal waters, either under background conditions, or during the eddy-induced phytoplankton bloom. This is particularly evident in Fig. 12. In these plots $\tilde{b}_{\mathrm{bp}}$ is plotted against $[\mathrm{chl}] / c_{\mathrm{p}}$, combining information from both Figs. 8 and 10. The data shown in the two scatterplots are not binned and they are grouped into different depth intervals (color coded) depending on the different ecological communities. For Cast 35 (Fig. 12a), $\tilde{b}_{\text {bp }}$ shows the presence of a surface $(0$ to $\approx 80 \mathrm{~m}$ depth) and intermediate layer (from $\approx 80$ to $\approx 120 \mathrm{~m}$ depth) characterized by slightly different values, both indicating the presence of small sized phytoplankton. Within the two layers $\tilde{b}_{\mathrm{bp}}$ remains constant. This might reflect a change from surface- to depth-adapted species. On the other hand, $[\mathrm{chl}] / c_{\mathrm{p}}$ steadily increases with depth. Since values of the backscattering ratio indicate the presence of a small sized phytoplankton community throughout the whole water column, this confirms that the increase of $[\mathrm{chl}] / c_{\mathrm{p}}$ reflects an increase in chlorophyll concentration per cell due to photoadaptation. For Cast 31, Fig. 12b shows that the shift in community structure from small phytoplankton to diatoms below $50 \mathrm{~m}$ (evidenced by the minimum in $\tilde{b}_{\mathrm{bp}}$ ), is characterized by roughly constant values of $[\mathrm{chl}] / c_{\mathrm{p}}$. [chl] $/ c_{\mathrm{p}}$ starts to increase below $\approx 63 \mathrm{~m}$ depth. This variation might result from the observed change in community, but even if so, it cannot be distinguished from the increase in $[\mathrm{chl}] / c_{\mathrm{p}}$ induced by photoadaptation. In both panels of Fig. 12, the increase observed in $\tilde{b}_{\text {bp }}$ at the top of the deep layer may reflect the enhanced remineralization processes occurring below the DCML.

This study shows that, despite some limitations, optical properties, and $\tilde{b}_{\mathrm{bp}}$ in particular, can be successfully used to obtain information about the composition of the suspended particles in the water column in Case I waters. Knowledge of the vertical distribution of the suspended material from the analysis of collected water samples was crucial in order to couple the optical signature of a given depth interval to a specific biogeochemical state. However, the good correspondence between optical properties and the ecological structure within the water column, both inside and outside cyclone Opal, suggests that in the near future, with increasing numbers of experiments studying the relationships between optical and biogeochemical characteristics under different conditions, continuous in situ optical measurements could be successfully used to obtain information on bulk 
particle compositions. Such information are of great importance to better understand physical-biogeochemical interactions within mesoscale eddies, and their role in governing the biogeochemical cycles in the open ocean.

Acknowledgements. Data used for this study were collected during the National Science Foundation (NSF) E-Flux experiment under a grant from the NSF Ocean Chemistry Program to Tommy Dickey. Dickey also received support from the NOPP MOSEAN project for the optical package, and his Secretary of the Navy/Chief of Naval Operations Chair in Oceanographic Sciences for his contribution to this paper. Funding for Francesco Nencioli was also provided by these grant. We thank all of the E-Flux project collaborators for their intellectual contributions and sharing of ideas. Special thanks to the two anonymous reviewers, whose comments and suggestions greatly improved the quality of this work. Wil Black provided considerable assistance with the calibration of the optical instruments and the deployment of the profiling package. Casey Moore of WET Labs is thanked for his assistance and the use of the optics package for this research.

Edited by: E. Boss

\section{References}

Babin, M. and Stramski, D.: Light absorption by aquatic particles in the near-infrared spectral region, Limnol. Oceanogr, 47, 911915, 2002.

Behrenfeld, M., Boss, E., Siegel, D., and Shea, D.: Carbonbased ocean productivity and phytoplankton physiology from space, Global Biogeochem. Cy., 19(1), GB1006, doi:10.1029/2004GB002299, 2005.

Benitez-Nelson, C., Bidigare, R. R., Dickey, T. D., Landry, M. R., Leonard, C. L., Brown, S. L., Nencioli, F., Rii, Y. M., Maiti, K., Becker, J. W., Bibby, T. S., Black, W., Cai, W. J., Carlson, C. A., Chen, F., Kuwahara, V. S., Mahaffey, C., McAndrew, P. M., Quay, P. D., Rappe, M. S., Selph, K. E., Simmons, M. P., and Yang, E. J.: Mesoscale eddies drive increased silica export in the subtropical Pacific Ocean, Science, 316, 1017-1020, 2007.

Boss, E., Pegau, W., Gardner, W., Zaneveld, J., Barnard, A., Twardowski, M., Chang, G., and Dickey, T.: Spectral particulate attenuation and particle size distribution in the bottom boundary layer of a continental shelf, J. Geophys. Res., 106, 9509-9516, 2001a.

Boss, E., Twardowski, M., and Herring, S.: Shape of the particulate beam attenuation spectrum and its inversion to obtain the shape of the particulate size distribution, Appl. Optics, 40, 4885-4893, $2001 b$.

Boss, E., Pegau, W., Lee, M., Twardowski, M., Shybanov, E., Korotaev, G., and Baratange, F.: Particulate backscattering ratio at LEO 15 and its use to study particle composition and distribution, J. Geophys. Res.-Oceans, 109(C1), C01014, doi:10.1029/2002JC001514, 2004.

Boss, E. S., Collier, R., Larson, G., Fennel, K., and Pegau, W. S.: Measurements of spectral optical properties and their relation to biogeochemical variables and processes in Crater Lake, Crater Lake National Park, OR, Hydrobiologia, 574, 149-159, doi:10.1007/s10750-006-2609-3, 2007.
Bricaud, A. and Stramski, D.: Spectral absorption-coefficients of living phytoplankton and nonalgal biogenus matter - a comparison between the Peru upwelling area and the Sargasso Sea, Limnol. Oceanogr., 35, 562-582, 1990.

Bricaud, A., Morel, A., and Prieur, L.: Absorption by dissolved organic-matter of the sea (yellow substance) in the UV and visible domains, Limnol. Oceanogr., 26, 43-53, 1981.

Brown, S. L., Landry, M. R., and Selph, K. E.: Diatoms in the desert, Deep-Sea Res. Pt. II, 55, 1321-1333, 2008.

Buiteveld, H., Hakvoort, J. H. M., and Donze, M.: The optical properties of pure water, SPIE Ocean Optics, 174-183, 1994.

Campbell, L. and Vaulot, D.: Photosynthetic picoplankton community structure in the subtraopical North Pacific-Ocean near Hawaii (Station ALOHA), Deep-Sea Res. Pt. I, 40, 2043-2060, 1993.

Chavanne, C., Flament, P., Lumpkin, R., Dousset, B., and Bentamy, A.: Scatterometer observations of wind variations induced by oceanic islands: Implications for wind-driven ocean circulation, Can. J. Remote Sens., 28(3), 466-474, 2002.

Dickey, T. D., Nencioli, F., Kuwahara, V. S., Leonard, C. L., Black, W., Bidigare, R. R., Rii, Y. M., and Zhang, Q.: Physical and bio-optical observations of oceanic cyclones west of the island of Hawai'i, Deep-Sea Res. Pt. II, 55, 1195-1217, 2008.

Eisner, L., Twardowski, M., Cowles, T., and Perry, M.: Resolving phytoplankton photoprotective : photosynthetic carotenoid ratios on fine scales using in situ spectral absorption measurements, Limnol. Oceanogr., 48, 632-646, 2003.

Falkowski, P. G., Ziemann, D., Kolber, Z., and Bienfang, P. K.: Role of eddy pumping in enhancing primary production in the ocean, Nature, 352, 55-58, 1991.

Fennel, K. and Boss, E.: Subsurface maxima of phytoplankton and chlorophyll: steady-state solutions from a simple model, Limnol. Oceanogr., 48, 1521-1534, 2003.

Huot, Y., Babin, M., Bruyant, F., Grob, C., Twardowski, M., and Claustre, H.: Relationship between photosynthetic parameters and different proxies of phytoplankton biomass in the subtropical ocean, Biogeosciences, 4, 853-868, 2007, http://www.biogeosciences.net/4/853/2007/.

Huot, Y., Morel, A., Twardowski, M., Stramski, D., and Reynolds, R.: Particle optical backscattering along a chlorophyll gradient in the upper layer of the eastern South Pacific Ocean, Biogeosciences, 5, 495-507, 2008, http://www.biogeosciences.net/5/495/2008/.

Kitchen, J. C. and Zaneveld, J. R. V.: On the noncorrelation of the vertical structure of light scattering and chlorophyll a in Case I waters, J. Geophys. Res., 95(C11), 20237-20246, doi:10.1029/JC095iC11p20237, 1990.

Landry, M. R., Brown, K. E., Selph, K. E., Simmons, M. P., and Rii, Y. M.: Depth-stratified phytoplankton dynamics in Cyclone Opal, a subtropical mesoscale eddy, Deep-Sea Res. Pt. II, 55, 1348-1359, 2008.

Lumpkin, C. F.: Eddies and currents in the Hawaii Islands, Ph.d. thesis, University of Hawaii at Manoa, Honolulu, USA, 1998.

McGillicuddy, D. J., Robinson, A. R., Siegel, D. A., Jannasch, H. W., Johnson, R., Dickey, T. D., McNeil, J. D., Michaels, A. F., and Knap, A. H.: Influence of mesoscale eddies on new production in the Sargasso Sea, Nature, 394, 263-266, 1998.

McNeil, J. D., Jannasch, H. W., Dickey, T. D., McGillicuddy, D. J., Brzezinski, M., and Sakamoto, C. M.: New chemical, bio-optical 
and physical observations of upper ocean response to the passage of a mesoscale eddy off Bermuda, J. Geophys. Res., 104, 1553715548, 1999.

Morel, A.: Optical properties of pure water and pure seawater, Academic, New York, 1974.

Morel, A.: Optical modeling of the upper ocean in relation to its biogenous matter content (Case I waters), J. Geophys. Res., 93(C9), 10749-10768, 1988.

Morel, A., Gentili, B., Claustre, H., Babin, M., Bricaud, A., Ras, J., and Tieche, F.: Optical properties of the "clearest" natural waters, Limnol. Oceanogr., 52, 217-229, 2007.

Nelson, N., Siegel, D., Carlson, C., Swan, C., Smethie, W., and Khatiwala, S.: Global distribution and dynamics of colored dissolved and detrital organic materials, Deep-Sea Res. Pt. I, 54, 710-731, doi:10.1016/j.dsr.2007.02.006, 2007.

Nencioli, F., Kuwahara, V. S., Dickey, T. D., Rii, Y. M., and Bidigare, R. R.: Physical dynamics and biological implications of a mesoscale eddy in the lee of Hawai'i: Cyclone Opal observations during E-Flux III, Deep-Sea Res. Pt. II, 55, 1252-1274, 2008.

Patzert, W. C.: Eddies in Hawaiian Islands, Report HIG-69-8, Hawaii Institute of Geophysics, University of Hawaii, Honolulu, USA, 1969.

Rii, Y. M., Brown, S. L., Nencioli, F., Kuwahara, V. S., Dickey, T. D., Karl, D. M., and Bidigare, R. R.: The transient oasis: nutrient-phytoplankton dynamics and particle export in Hawaiian lee cyclones, Deep-Sea Res. Pt. II, 55, 1275-1290, 2008.

Siegel, D., Maritorena, S., Nelson, N., Hansell, D., and LorenziKayser, M.: Global distribution and dynamics of colored dissolved and detrital organic materials, J. Geophys. Res.-Oceans, 107(C12), 21-1-14, doi:10.1029/2001JC000965, 2002.
Siegel, D. A., Dickey, T. D., Washburn, L., Hamilton, M. K., and Mitchell, B. G.: Optical determination of particulate abundance and production variations in the oligotrophic ocean, Deep-Sea Res. Pt. I, 36, 211-222, 1989.

Sullivan, J., Twardowski, M., Zaneveld, J., Moore, C., Barnard, A., Donaghay, P., and Rhoades, B.: Hyperspectral temperature and salt dependencies of absorption by water and heavy water in the 400-750 nm spectral range, Appl. Optics, 45, 5294-5309, 2006.

Twardowski, M., Boss, E., Macdonald, J., Pegau, W., Barnard, A., and Zaneveld, J.: A model for estimating bulk refractive index from the optical backscattering ratio and the implications for understanding particle composition in case I and case II waters, J. Geophys. Res.-Oceans, 106, 14129-14142, 2001.

Twardowski, M., Claustre, H., Freeman, S., Stramski, D., and Huot, Y.: Optical backscattering properties of the "clearest" natural waters, Biogeosciences, 4, 1041-1058, 2007, http://www.biogeosciences.net/4/1041/2007/.

Twardowski, M. S., Boss, E., Sullivan, J. M., and Donaghay, P. L.: Modeling the spectral shape of absorption by chromophoric dissolved organic matter, Mar. Chem., 89, 69-88, 2004.

Yamashita, Y. and Tanoue, E.: Basin scale distribution of chromophoric dissolved organic matter in the Pacific Ocean, Limnol. Oceanogr., 54, 598-609, 2009.

Zaneveld, J. R. V., Kitchen, J. C., and Moore, C. M.: The scattering error correction of reflecting tube absorption meters, Ocean Optics XII, 44-55, 1994. 